\title{
Probing Carrier Behavior at the Nanoscale in Gallium Nitride using Low Voltage Cathodoluminescence
}

\author{
M. R. Phillips*, D. Drouin** and N. Pauc** \\ * Microstructural Analysis Unit, University of Technology, Sydney, PO Box 123, Broadway NSW \\ 2007 Australia \\ ** Université de Sherbrooke, 2500 Bd de l'université, J1K 2R1, Sherbrooke, Québec, Canada
}

The increasing application of $\mathrm{GaN}$ in blue and UV light emitting diodes and lasers has generated considerable interest in its optical and electrical properties. These optical devices exhibit extremely high emission efficiencies despite the presence of a very high concentration of threading dislocations $\left(10^{8}-10^{10} \mathrm{~cm}^{-2}\right)$ that act as non-radiative recombination channels. This perceived contradiction can be been explained by small $(<100 \mathrm{~nm})$ carrier diffusion lengths which effectively negate the effect of the threading dislocations on the radiative recombination efficiency. These short exciton and minority carrier diffusion lengths in $\mathrm{GaN}$ can be explored by cathodoluminescence (CL) microscopy and spectroscopy using a SEM equipped with a Schottky field emission gun operating at $1 \mathrm{kV}$.

The recombination length $(\mathrm{L})$ be estimated by analyzing the $\mathrm{CL}$ contrast around isolated threading dislocations which varies as $\mathrm{C}(\mathrm{r}) \propto \exp (-\mathrm{r} / \mathrm{L})$, where $\mathrm{r}$ is the distance of the electron probe from the dislocation core. Monte Carlo simulation of the normalized depth and radial total energy loss profiles (Figure 1) reveal that at $1 \mathrm{kV}$ minority carriers are injected into a $<10 \mathrm{~nm}$ volume in $\mathrm{GaN}$. The diffusion length for bound excitons $\left(\mathrm{D}^{\circ} \mathrm{X}\right)$ and free excitons (FX) can be determined by using the near band edge CL emission at $5 \mathrm{~K}$ and $300 \mathrm{~K}$, respectively. Minority carrier diffusion can be measured using deep level CL, such as free-to-bound $\left(\mathrm{D}^{\circ} \mathrm{h}\right)$ emission at $300 \mathrm{~K}$ and donor acceptor pair (DAP) emission at $100 \mathrm{~K}$. Panchromatic CL images at $5 \mathrm{~K}$ of undoped $\left(\mathrm{n}_{\mathrm{e}} \approx 1.0 \times 10^{16} \mathrm{~cm}^{-3}\right)$ and $\mathrm{GaN}: \mathrm{Si}\left(\mathrm{n}_{\mathrm{e}} \approx 3.5 \times 10^{18} \mathrm{~cm}^{-3}\right)$ collected under identical excitation conditions are shown in Figure 2 (undoped $\mathrm{GaN}$ ) and Figure $3(\mathrm{GaN}: \mathrm{Si})$. $\mathrm{A} \mathrm{D}^{\circ} \mathrm{X}$ diffusion length of $\approx 50 \mathrm{~nm}$ was observed in the $\mathrm{GaN}: \mathrm{Si}$ compared to $\approx 90 \mathrm{~nm}$ in undoped $\mathrm{GaN}$. This difference can be accounted for by higher donor concentration in $\mathrm{GaN}: \mathrm{Si}$. Larger recombination lengths were found for the FX $(\approx 80 \mathrm{~nm})$ and for minority carriers $(\approx 100 \mathrm{~nm})$. The FX recombination length is essentially determined by how quickly the FX loses its kinetic energy by phonon emission whereas the minority carrier diffusion length is strongly affected by carrier mobility.

Since $\mathrm{GaN}$ has a bare surface potential of $\approx 1 \mathrm{eV}$, depletion layer depths of $\approx 17 \mathrm{~nm}$ for $\mathrm{GaN}: \mathrm{Si}$ and $\approx 100 \mathrm{~nm}$ for the undoped $\mathrm{GaN}$ are expected at the $\mathrm{GaN}$ surface. The exciton binding energy $\left(\mathrm{E}_{\mathrm{B}}\right)$ and Bohr radius $\left(\mathrm{a}_{\mathrm{B}}\right)$ of the $1 \mathrm{~S}$ state in $\mathrm{GaN}$ is $25 \mathrm{meV}$ and $2.3 \mathrm{~nm}$ respectively. Consequently excitons will be separated into electron hole pairs when the surface field surpasses the exciton ionization field $\left(\mathrm{E}_{\mathrm{i}}=\mathrm{E}_{\mathrm{B}} / \mathrm{a}_{\mathrm{B}}=1.1 \times 10^{5} \mathrm{~V} / \mathrm{cm}\right)$. $\mathrm{E}_{\mathrm{i}}$ is exceeded at depths up to $\approx 15 \mathrm{~nm}$ in GaN:Si and $\approx 46 \mathrm{~nm}$ in the undoped sample, suggesting that at $1 \mathrm{kV}$ no $\mathrm{FX}$ or $\mathrm{D}^{\circ} \mathrm{X} C \mathrm{CL}$ emission should be observed as all carriers injected within the exciton ionization range will be separated by the surface field. The FX CL intensity versus $I_{B}$ at $300 \mathrm{~K}$ (Figure 4) shows no indication of exciton dissociation, 
exhibiting a power density dependence, $\mathrm{I}_{\mathrm{CL}} \propto \mathrm{I}_{\mathrm{B}}{ }^{\mathrm{n}}$, with a power law exponent of $\mathrm{n} \approx 0.9$ over a wide range of $I_{B}(100$ to $1000 \mathrm{pA})$. This result suggests that flat band conditions exist during electron irradiation. Since all carriers are injected within the depletion layer, holes are rapidly swept to the surface by the in-built surface field and captured by surface states, reducing the depletion layer width towards zero.

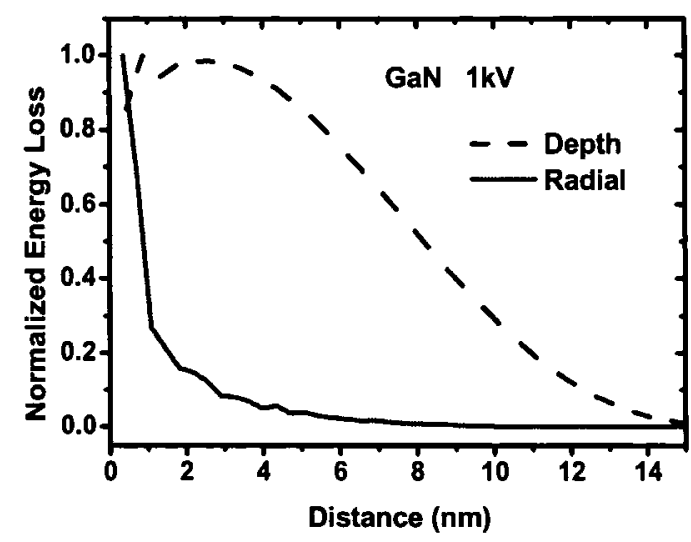

Fig. 1. Normalized depth and radial energy loss profiles for $\mathrm{GaN}$ at $1 \mathrm{kV}$ including a $1 \mathrm{~nm}$ surface layer of $\mathrm{Ga}_{2} \mathrm{O}_{3}$

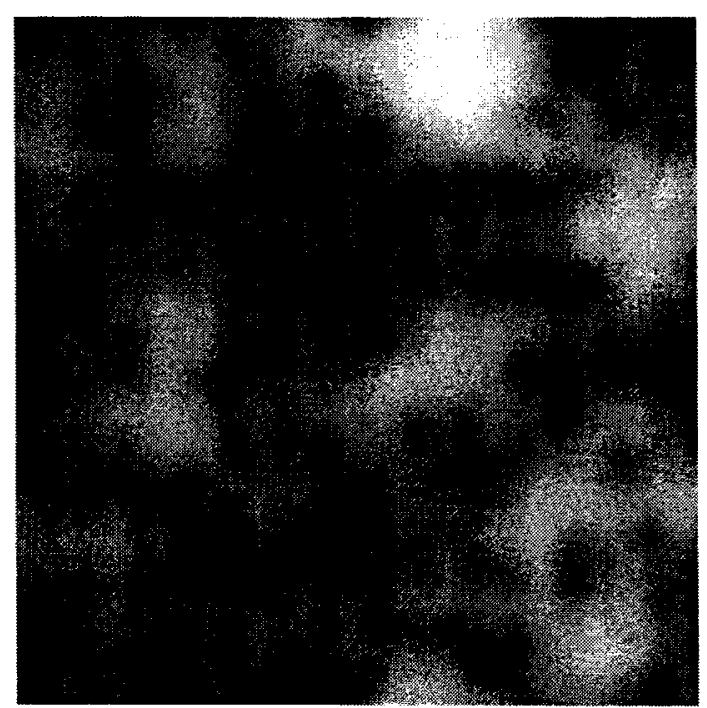

Fig. 3. Panchromatic $\mathrm{D}^{\circ} \mathrm{X}$ CL image of threading dislocations in $\mathrm{GaN}: \mathrm{Si} 1 \mathrm{kV}, 0.4 \mathrm{nA}$, $2 \mu \mathrm{m} \times 2 \mu \mathrm{m}$

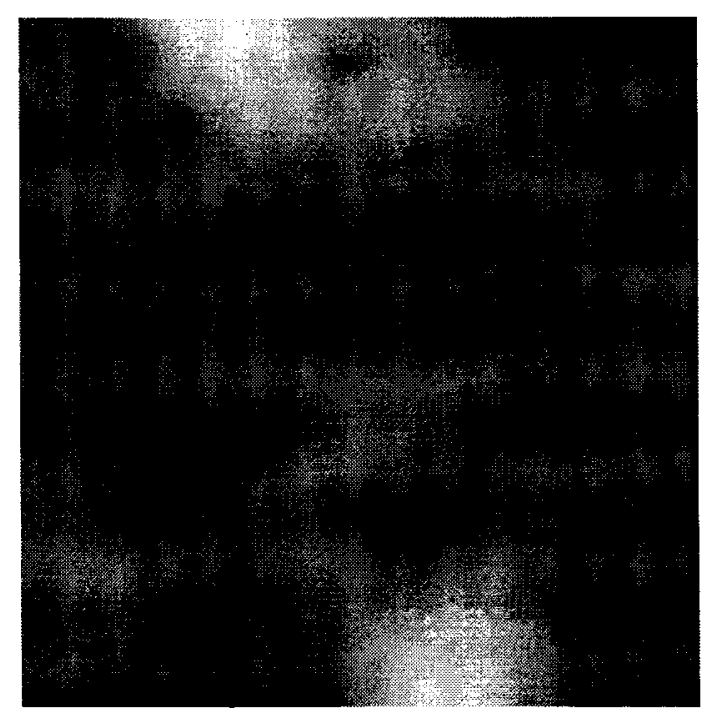

Fig. 2. Panchromatic $\mathrm{D}^{\circ} \mathrm{X}$ CL image of threading dislocations undoped $\mathrm{GaN} 1 \mathrm{kV}$, $0.4 \mathrm{nA}, 2 \mu \mathrm{m} \times 2 \mu \mathrm{m}$

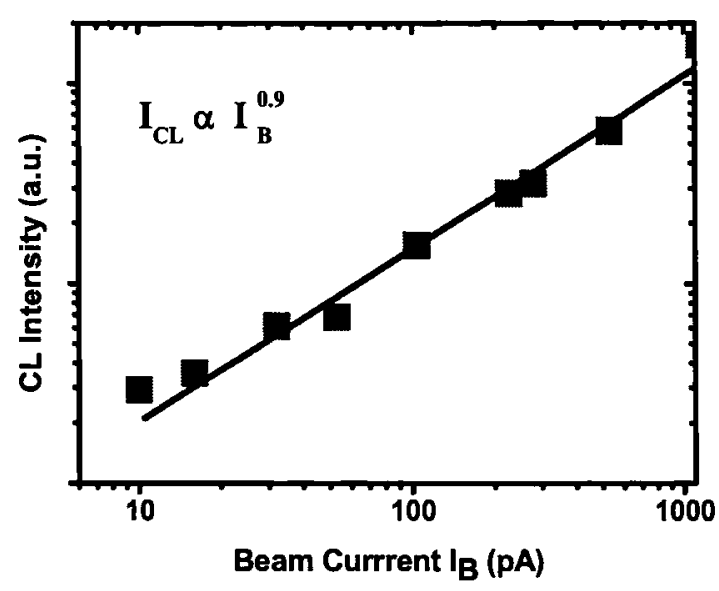

Fig. 4. FX CL intensity versus $I_{B}$ at $1 \mathrm{kV}$ and $300 \mathrm{~K}$ 
Proceedings
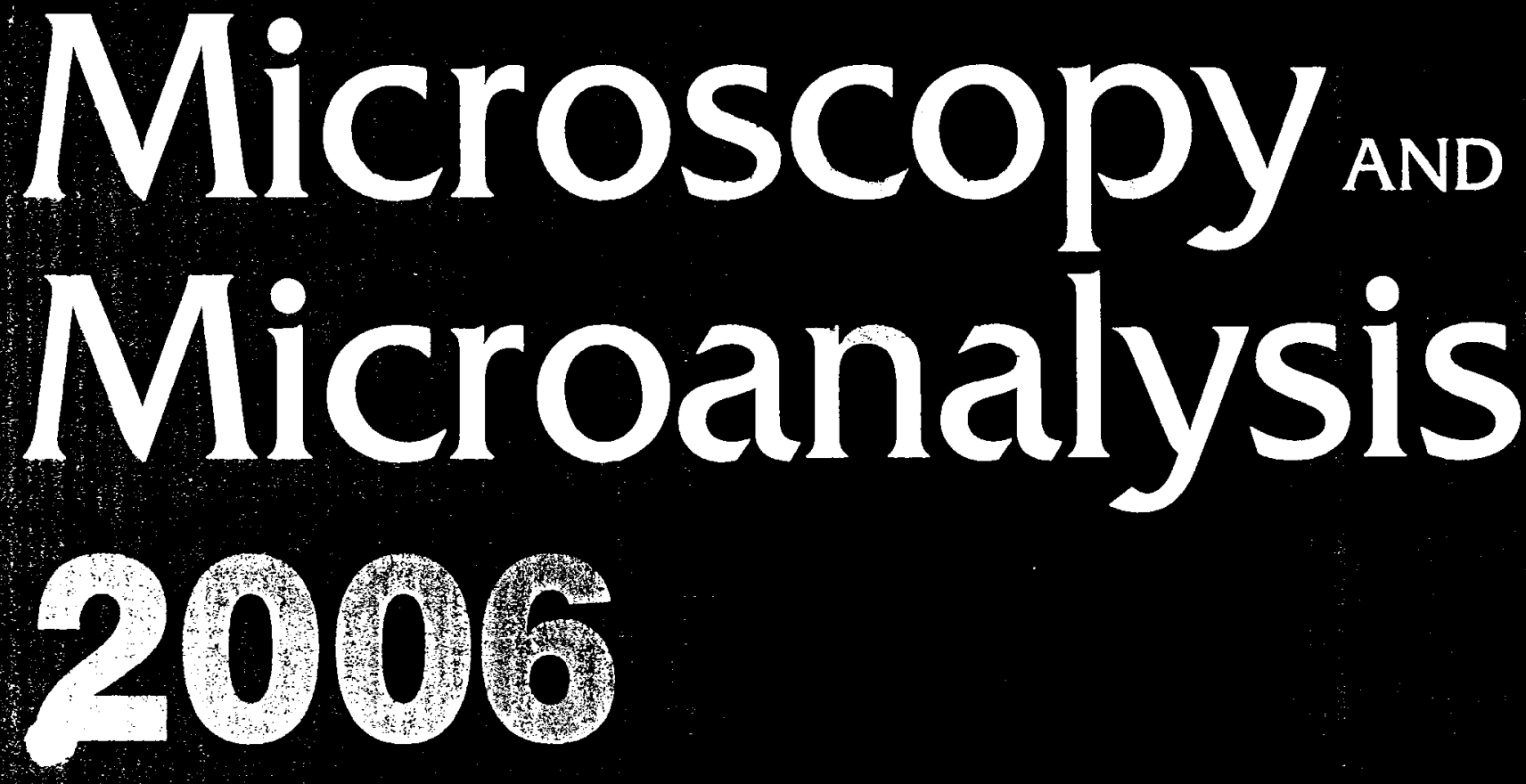

Edited by

Chicago, Illinois, USA

P. KOTULA July 30-August 3, 2006

M. MARKO J.-H. SCOTT

R. GAUVIN

D. BENIAC

G. LUCAS

S. MCKERNAN

J. SHIELDS

Published By

Cambridge University Press

Microscopy Society of America

64th Annual Meeting

Microbeam Analysis Society

40th Annual Meeting

International Metallographic Society

39th Annual Meeting

Microscopical Society of Canada/

Société de Microscopie du Canada

33rd Annual Meeting

Microscopy and Microanalysis, Volume 12, Supplement 2, 2006 